\section{VAN DE REDACTIE}

\section{Vernieuwing}

Reeds geruimen tijd is de Redactie erop bedacht, aan de bedrijfseconomische vraagstukken een ruimere plaats toe te kennen en aldus vooral de wetenschappelijke beoefening der bedrijfshuishoudkunde te bevorderen. $Z_{i j}$ meent, dat het oogenblik gekomen is haar streven in deze richting op stellige wijze tot uiting te brengen en heeft daarom in overleg met den uitgever besloten met ingang van den nieuwen jaargang een uitbreiding te geven aan den omvang van dit tijdschrift en het voortaan op gezette wijze de specifiek bedrijfseconomische problemen te doen behandelen. Met handhaving van de beteekenis van het blad op het gebied der accountancy hoopt de Redactie dus voortaan ook aan de bedrijfseconomie de plaats te geven, welke haar naar opzet en titel van het M.A.B. toekomt.

De Redactie durft de gereeder tot dezen stap over te gaan. omdat haar uit de kringen van de beoefenaars der bedrijfseconomie gebleken is van een verlangen naar een tribune, waar zij de resultaten van hun arbeid bij tijd en wijle in goed gezelschap kunnen openbaar maken. De Redactie vertrouwt daarom, dat zij op belangstelling en vooral medewerking uit dezen kring zal kunnen rekenen.

Intusschen ligt het in het voornemen, teneinde aan den nieuwen opzet een stevigen grondslag te geven, een aantal bedrijfs-economen uit te noodigen, in vast verband met het M.A.B. over bedrijfs-economische problemen te schrijven.

In de Januari-aflevering 1941 zal mededeeling worden gedaan van de namen van hen, die de Redactie bereid heeft gevonden om den door haar beoogden nieuwen opzet te helpen verwezenlijken.

Ook nog om een andere reden zal de eerste aflevering van den 18en jaargang de aandacht van de lezers verdienen. Met ingang van die aflevering zal het M.A.B., wat den inhoud betreft, in grooteren omvang gaan verschijnen, doch wat het formaat betreft worden gebracht op het veel handzamere boekformaat. Voorts zal de rubriek Examenvraagstukken niet meer in de afleveringen worden opgenomen, doch kwartaalsgewijze als bijlage aan de afleveringen worden toegevoegd.

De Redactie hoopt en verwacht, dat deze wijzigingen bij de lezers een gunstig onthaal zullen vinden en als even zoovele verbeteringen zullen worden beschouwd.

Aan den uitgever, den Heer J. Mutusses, brengt de Redactie dank voor de voortvarendheid, waarmede deze zich beijverd heeft om aan alle wenschen van de Redactie in het belang van een gestadige vernieuwing en van een accentueering van het wetenschappelijke karakter van het M.A.B. tegemoet te komen.

\section{Pimentel}

Met het einde van het jaar 1940 treedt de heer Pimentel uit de Redactie van dit tijdschrift. Wegens zijn verblijf in het buitenland is hij in de onmogelijkheid deel te nemen aan den redactioneelen arbeid en wij geven daarom thans gevolg aan het bij zijn vertrek in het begin van dit jaar geuite verlangen tot ontslag uit zijn functie van Redacteur.

Wij doen dit met groot leedwezen. In den kring der Redactie is de heer Pimentel, die van de oprichting af daarin zitting had, hoog gewaardeerd om zijn bezonken oordeel en zijn praktischen zin. Onze beste wenschen vergezellen hem.
DE SAMENWERKING TUSSCHEN WISKUNDIG ADVISEUR EN ACCOUNTANT IN HET LEVENSVERZEKERINGSBEDRIJF

Het is bij Nederlandsche levensverzekeringsmaatschappijen gebruikelijk, dat het jaarverslag o.m. vergezeld gaat van twee verklaringen, nl. één van een actuaris en één van een accountant.

Zeer in het kort gezegd verklaart eerstgenoemde, dat de premiereserve tot het in de balans genoemde bedrag juist is bepaald en de tweede, dat hij — steunende op eerstbedoelde verklaring - de geheele jaarrekening goedkeurt.

Wij zien hierbij af van een critisch onderzoek naar de redactie dezer verklaringen, welke een bijna even groote verscheidenheid vertoont als er levensverzekeringsmaatschappijen bestaan. Het gaat er thans niet om om na te gaan, of sommige dezer redacties, juridisch beschouwd, wellicht ruimte laten voor een eenigszins afwijkende interpretatie - een kwestie, die natuurlijk ter sprake zou komen als in geval van gebleken onjuistheden de aansprakelijkheid zou moeten worden vastgesteld - doch slechts om vast te stellen wat de algemeene strekking der verklaringen is en hoe die o.i. door de belanghebbenden worden opgevat.

Zou dus in bepaalde gevallen blijken, dat de redactie niet volledig hiermede in overeenstemming was, dan zou de eenige consequentie zijn dat de redactie verbetering behoefde.

Zoo gezien nemen wij aan, dat de verklaring van den accountant erop neerkomt, dat hij de boekhouding en - in aansluiting daarop - alle posten der Balans en Winstrekening, met uitzondering echter van de posten Premiereserve, zoo volledig gecontroleerd heeft als de regels van zijn vak hem dit voorschrijven, doch dat hij, wat evengenoemde posten (in de Balans en in de Winstrekening) betreft slechts heeft nagegaan, dat de bedragen in overeenstemming zijn met het door den actuaris in zijn verklaring genoemde bedrag.

Voor de materiaale juistheid van dit bedrag draagt niet hij, doch de wiskundige de verantwoordelijkheid.

Wij meenen bij de bespreking van het probleem, waarover de Redactie ons verzocht heeft onze meening te zeggen, van dit gebruik te mogen uitgaan.

De vroeger wel eens aan de orde gestelde vraag of een dergelijke taakverdeeling juist is met name of het niet juister ware dat de accountant - voor zoover noodig, na een daarop berekende opleiding - de volledige contrôle der balans, dus met inbegrip van den post wiskundige reserve, op zich nam, kan dus onbesproken blijven. In laatstbedoeld geval toch zou er van samenwerking geen sprake zijn.

In de door ons veronderstelde verhouding bestaat er samenwerking in dien zin, dat beide functionarissen elk met een hun toegewezen taak samenwerken tot hetzelfde doel, nl. zekerheid te verschaffen voor, vertrouwen te wekken in, voor zoover noodig, belanghebbenden gerust te stellen omtrent de door het Bestuur te verrichten publicatie. Men zou deze samenwerking compleet kunnen achten door bovenvermelde, weinig tijd vereischende doch principieel belangrijke, schakelfunctie van den accountant, nl. dat hij moet vaststellen dat in de Balans (passief) en Winstrekening (debetzijde) inderdaad het door den actuaris goedgekeurde bedrag werd opgenomen.

Hij kan daardoor, als het ware, tot de belanghebbenden zeggen: ,Indien Ge overtuigd zijt van ons beider betrouwbaarheid en vertrouwen stelt in de actueele capaciteiten van den Heer ...... en in mijn contrôlecapaciteiten, dan kunt Ge aannemen, dat de gepubliceerde jaarrekening juist is." 
Bezien wij voorloopig de samenwerking uitsluitend van dit standpunt, dan geldt hiervoor de algemeene regel, dat men als fatsoenlijk mensch en als, zijn eigen vak beheerschend, deskundige slechts zal willen samenwerken met iemand, van wien men in beide opzichten dezelfde standing veronderstelt, van wien men dus aanneemt, dat hij zoowel den goeden wil als de noodige bekwaamheid heeft om zich van het hem toegewezen deel der taak te kwijten. In de practijk zullen uit dezen regel slechts bij excessen consequenties getrokken (kunnen) worden. Daaruit een soort collectieve verantwoordelijkheid af te leiden zou absurd zijn daar het systeem juist gebaseerd is op de veronderstelling dat men op elkaar's terrein niet deskundig is en dus elkaars werk niet kan beoordeelen.

In het bovenstaande hebben wij aangenomen, dat de beide deskundige-verklaringen worden afgegeven door personen werkzaam in het vrije beroep, althans niet in dienstbetrekking bij de betrokken onderneming.

Wat den accountant betreft is ons in dit bedrijf geen voorbeeld bekend, waarin dit laatste wel het geval zou zijn. Wel is het bij sommige maatschappijen gebruikelijk, dat de actuarieele verklaring wordt afgegeven door een lid van het personeel. 1)

Men moge over de waarde eener dergelijke verklaring van meening verschillen, vast staat o.i., dat daaraan nimmer dezelfde beteekenis gehecht kan worden als aan die van den buitenstaander 1). Van het wekken van vertrouwen in de publicatie der Directie of van samenwerking met den accountant tot dat doel kan o.i. geen sprake zijn. Het zou een beleediging zijn voor de Directie te veronderstellen, dat belanghebbenden daartoe meer prijs zouden stellen op de handteekening van een haar ondergeschikt persoon dan dat de Directie, na intern ingewonnen advies op de wijze als dit voor alle onderdeelen der publicatie zal plaats vinden, uitsluitend zelf de verantwoordelijkheid op zich neemt.

Sommige accountants hebben uit deze overweging de conclusie getrokken, dat $z i j$ in dit geval niet naar de verklaring van den actuaris mogen verwijzen mar nar een weg moeten zoeken om de verantwoordelijkheid voor de geheele jaarrekening - dus ook voor den post Wiskundige Reserve - te kunnen dragen. Als middel daartoe wordt dan aanbevolen, dat de accountant, voor zoover deze geacht moet worden zelf de hiertoe noodige kennis te missen, persoonlijk de hulp inroept van een deskundige, die wel over de noodige onafhankelijkheid zou beschikken. Wij weten niet of deze, in theorie aanbevolen. oplossing inderdaad wordt toegepast. Het wil ons wat onwaarschijnlijk voorkomen, dat een Bestuur, dat voor zijn eigen publicatie meent een onderzoek door een buitenstaand wiskundige te kunnen ontberen, wel bereid zou zijn de kosten daarvan aan den accountant te vergoeden en aangezien deze laatste die toch ook bezwaarlijk voor eigen rekening zal kunnen nemen, zal een weigering om op deze verklaring te steunen gelijk staan met het weigeren der opdracht. Wij zouden het laatste slechts dan noorzakelijk achten, wanneer ten onrechte de indruk gevestigd werd alsof actuaris en accountant in gelijke verhouding tegenover het Bestuur stonden. Een lid van het N.I.v.A., dat zonder meer verwijst naar de verklaring van een ambtenaar en daarbij den schijn wekt te verwijzen naar de verklaring van een buitenstaand deskundige, handelt naar onze meening in strijd, zoo niet met de letter, dan toch met den geest van het Reglement van Arbeid dezer Vereeniging.

Voor het overige zou de beoordeeling of er behoefte bestaat aan een verklaring van buitenstaand actuaris, hoe onze per-

1) Ten onrechte o.i. duidt men dit verschil vaak aan met de woorden "afhankelijk" en .onafhankelijk". In materieelen $z$ in is niemand geheel onafhankelijk, in moreelen zin kan iedereen het zijn. woonlijke meening daarover ook moge zijn, aan belanghebbenden, in laatste instantie aan de Verzekerigkamer kunnen worden overgelaten.

Wanneer men leest, wat in accountantskringen omtrent het onderhavige onderwerp is gepubliceerd (wij verwijzen o.a. naar de op 22 November 1930 voor het N. I. v. A. gehouden inleiding van wijlen collega de Goey en de daarop gevolgde debaten), dan blijkt dat regelmatig een veel intensievere samenwerking ter sprake komt dan hierboven besproken is.

Vrij algemeen blijkt de overtuiging te bestaan, dat de accountant, hoezeer hij niet verantwoordelijk is voor de juiste berekening der premiereserve, toch ook niet geheel onverschillig daartegenover mag staan, met name dat hij wel eenige verantwoordelijkheid ervoor zou dragen, dat alle loopende verzekeringen in deze berekening zijn opgenomen.

De Heer de Goey poneerde de volgende stelling:

.In ieder geval ( $\mathrm{nl}$. of er een verklaring van een buitenstaand actuaris is dan wel van een ambtenaar) zal de accountant zich moeten overtuigen, dat de verzekeringen, die op den balansdatum bestonden, in de berekening der reserve zijn begrepen."

In het debat werd er terecht op gewezen, dat de accountant zich daarvan alleen zou kunnen overtuigen door de berekening der reserve te controleeren en daar het geheele systeem erop gebaseerd is, dat de accountant niet geacht wordt daartoe de capaciteit te bezitten, is de onjuistheid dezer stelling vrijwel uit het ongerijmde bewezen.

$\mathrm{Bij}$ het debat bleek dan ook, dat de inleider het niet geheel zoo had bedoeld. Hij wilde zelfs niet zoo ver gaan, dat hij zich vereenigde met de door anderen aanbevolen procedure, nl. dat de accountant den wiskundigen adviseur de gegevens voor de berekening der premie-reserve zou moeten verschaffen (men denke niet te licht over het boekdeel, dat de accountant eener groote maatschappij den actuaris ter hand zou moeten stellen) noch zooals een der debaters het stelde, (hetgeen principieel op hetzelfde neerkomt,) dat de accountant er zich van moet overtuigen, dat de wiskundige al het materiaal heeft verkregen, dat hij moet hebben om de berekening te maken.

De inleider wilde zich blijkbaar vergenoegen met een onderzoek, hoe de wiskundige aan de gegevens is gekomen, opdat hij kan aannemen, dat de wiskundige adviseur met volkomen kennis van zaken zijn verklaring heeft kunnen teekenen.

Principieel lijkt ons de motiveering der bemoeienissen van den accountant met de premiereserve-berekening - onverschillig de nuances of hij de gegevens verstrekt, het verstrekken der gegevens controleert dan wel slechts onderzoekt, of hij kan aannemen, dat ze juist verstrekt zijn - niet sterk gefundeerd. $E_{\Gamma}$ is hier een scherp begrensde, duidelijk geformuleerde taakverdeeling met daarop aansluitende gesplitste verantwoordelijkheid en men behoeft niet aan te nemen, dat iemand de verklaringen zoo slecht leest, dat hij op grond van zijn vertrouwen in den accountant aanneemt, dat de reserve juist berekend is. Trouwens, zoo iemand zou ondanks de bovengeschetste maatregelen toch bedrogen uit kunnen komen.

Er is echter iets anders. Kunnen zoowel de accountant als de wiskundige hun eigen taak, nl, voor den eerste de contrōle der boekhouding en der Jaarrekening met deze ééne uitzondering, voor den tweede de contrôle der reserve-berekening goed uitvoeren zonder elkaar's hulp?

Bezien wij dit eerst voor den accountant. In den aanvang schreven wij, dat de accountant genoemde contröle zoo volledig moet uitvoeren als de regels van zijn vak hem voor- 
schrijven. In dit verband zullen de lezers van dit blad het met mij eens zijn, dat in de tegenwoordige contrōletechniek een steeds arootere plaats wordt ingeruimd aan de zgn. verbandsrontrôle. dat is de wijze van controleeren, waarbij de juisthe:d - of althans de aannemelijkheid - van bepaalde posten wordt beoordeeld aan de hand van een zeker verband, waarin deze staan tot andere posten.

De accountants komen steeds meer tot de overtuiging, dat contrôle aan de hand van bescheiden lang niet zoo afdoende is als men vroeger wel eens heeft gemeend en dat deze zelfs bijna volledig faalt, voor zoover het erom gaat vast te stellen, dat alle te boeken posten inderdaad geboekt zijn. De verbandcontrôle vormt hierop een niet alleen gewenschte, doch hoogst noodzakelijke aanvulling.

Het komt ons voor, dat er weinig bedrijfstakken zijn, waar de verbandcontrôle voor den accountant - trouwens evenzeer voor den internen controleur - van zoo groote beteekenis is als in het levensverzekeringsbedrijf.

Om slechts enkele voorname groepen van posten te noemen kan de contrōle der premie-ontvangsten, uitkeeringen, provisie-betalingen, rente-uitkeeringen, polisbeleeningen en van nog vele andere posten slechts behoorlijk plaats vinden door verband te leggen (op de techniek hiervan behoeven wij thans niet in te gaan) tusschen de geboekte ontvangsten of uitgaven en het zgn. ,,bestand", dat zijn de op een bepaald moment loopende levensverzekeringcontracten. Hiertoe moet dus regelmatig rekening worden gehouden met de in dit ,bestand" voorkomende mutaties, nl. nieuwe posten, royementen en wijzigingen.

Bij dit laatste nu gelieve men te bedenken, dat de accountant voor het vaststellen dezer mutaties voor een groot deel aangewezen is op interne contrôle.

Wij behooren niet tot degenen, die het gebruik maken van interne contrôle door den accountant zonder meer veroordeelen. Integendeel, wij meenen hier een voorbeeld te hebben aangeroerd, waarin hij daartoe genoodzaakt en - onder bepaalde voorwaarden - daartoe volkomen gerechtigd is. Doch tot deze voorwaarden behoort o.m., dat geen beschikbaar intern of extern contrôlemiddel ongebruikt wordt gelaten om de verkregen zekerheid te vergrooten

$\mathrm{Nu}$ heeft ook de berekenaar zoowel als de controleur der premiereserve met hetzelfde bovenbedoelde ,bestand" en met dezelfde mutaties te maken. Bij maatschappijen van eenigen omvang geschiedt de verzameling der gegevens tot dit doel in de afdeeling wiskunde min of meer los van de verzameling der hiermede verband houdende gegevens in de afdeeling, die zorg draagt voor de inning der kwitanties, de uitbetaling van provisie en incassoloon, enz., zij het dan dat ook de instanties der interne contrōle ervoor zullen waken, dat beide afdeelingen tot hetzelfde resultaat komen. Is de accountant nu niet verplicht, als sluitstuk zijner contröle op bovengenoemde posten, na te gaan of de interne contrôle hier goed gewerkt heeft, nota te nemen van het bestand, zooals dat ten behoeve der premiereserve-berekening is vastgesteld en door den wiskundigen adviseur is aangenomen, en zijn aanteekeningen betreffende dat bestand, waarop hij een groot deel zijner contrōle gebaseerd heeft, daaraan te toetsen?

De omstandigheid, dat alle benoodigde gegevens worden vastgelegd in den door den wiskundige mede-onderteekenden staat L 16, waarvan de accountant nota kan nemen zonder. bij wijze van spreken, ooit met dezen wiskundige kennis te hebben gemaakt, doet niets af aan het principe van samenwerking dat hier zeer zeker plaats vindt en waarbij de accountant de ontvangende partij is.

Ofschoon dit uit het bovenstaande reeds is af te leiden, willen wij nog even vaststellen, dat de accountant er zeker niet mee kan volstaan het door hem vastgelegde bestand, het- welk van zooveel belang is voor zijn verbandcontrôle, met staat L 16 te controleeren. Er bestaan nog tal van andere contrôle-middelen, doch deze vormen niet een zoodanig afgesloten geheel, dat wij het genoemde erbij zouden willen ontberen.

Wij komen nu tot de andere zijde van het vraagstuk. Ook de actuaris dient zich op de hoogte te stellen van de samenstelling van het bestand op den balansdatum. Hij heeft nog veel meer gegevens van noode, welke aan de boekhouding moeten worden ontleend, als daar zijn de werkelijk betaalde onkosten, de ontvangen interest, enz., enz. Kan de wiskundige daarbij niet exeneens een nuttig gebruik maken van hetgeen de accountant volgens diens werkmethode heeft vastgesteld en is het daarom niet evenzeer in zijn belang daartoe contact te zoeken met den accountant? Hij heeft daartoe - in tegenstelling tot den accoun tant - niet zonder meer de beschikking over een reeds afgegeven verklaring. Een groot deel der door hem benoodigde gegevens kunnen hem echter door den accountant aan de hand der reeds ten behoeve zijner eigen contrôle gemaakte aanteekeningen worden verstrekt. Voor zoover dit niet het geval is, kan de accountant zooveel mogelijk bij voorbaat met de behoeften van den actuaris rekening houden.

Zeker, alle door hem benoodigde gegevens zouden den actuaris door de Directie, door het personeel der onderneming verstrekt kunnen worden. Het komt ons echter voor niet te passen in het systeem van door buitenstaande deskundigen afgegeven verklaringen, dat één dezer verklaringen zou zijn gebaseerd op gegevens welke, zonder externe contrôle, door het personeel zijn verstrekt.

Hier zal echter de wiskundige moeten beslissen, of hij zonder samenwerking met den accountant de door hem aanvaarde verantwoordelijkheid kan dragen. Deze behoeft zijn diensten niet op te dringen: als certificeerend accountant aanvaardt hij geenerlei verantwoordelijkheid voor de juistheid der premiereserve. Een eventueele fout, het weglaten eener post met, per saldo, een groote uitkeeringsverplichting, het rekenen met een te hoogen opslag voor eerste kosten zou uitsluitend ter verantwoording komen van den certificeerenden actuaris doch wij stellen ons voor, dat hij deze verantwoordelijkheid niet zou kunnen noch willen dragen zonder alles te hebben gedaan wat in zijn macht is om zich van de juistheid der reserve te verzekeren, waartoe toch ook behoort, dat hij onder andere t.o.v, het bestand contact heeft gezocht met den externen accountant der maatschappij en aldus mede geprofiteerd heelt van de wetenschap, die deze gedurende zijn contrôle heeft opgedaan.

In de debatten, gehouden op bovenbedoelde ledenbijeenkomst van het N.I.v.A., is nog sprake geweest van een andere wijze van samenwerking. waarbij het echter niet gaat om samenwerking tusschen twee deskundigen, die een verklaring hebben af te geven, als zoodanig, doch uitsluitend om samenwerking tusschen een deskundige op comptabel met één op actuarieel gebied.

Wij denken hierbij aan een punt, hetwelk door één der debaters werd ter sprake gebracht en waarbij een woord genoemd werd, dat voor dergelijke samenwerking onmiddellijk een groot perspectief opent: organische winstrekening.

Inderdaad doen zich bij iedere poging tot het opstellen eener winstrekening, welke - meer dan de officieele L 1 kijk geeft op de resultaten van het bedrijf en op de splitsing van dit resultaat naar zijn factoren, een aantal comptabelactuarieele vraagstukken voor, die uitsluitend kunnen worden opgelost hetzij door iemand, die in beide vakken doorkneed zou zijn, hetzij in samenwerking tusschen twee personen, die 
tezamen over deze capaciteiten beschikken. Hetzelfde doet zich voor, indien men de boekhouding zoodanig wenscht in te richten, dat ze, meer dan gebruikelijk, gedurende den loop van het jaar een voortschrijdend overzicht der resultaten verschaft. Vergeleken met de boekhouding van andere bedrijven zegt die van vele levensverzekeringondernemingen gedurende den loop van het jaar als regel al bitter weinig. Noch de accountant q.q. noch de actuaris zal daarin alleen verbetering kunnen brengen. Het komt ons voor, dat door samenwerking der beide deskundigen in dit verband in het belang van het bedrijf nog veel te bereiken zou zijn.

R'dam, 20 Maart 1940.

JAMES POLAK.

\section{DE BANKWET EN DE BENOEMING VAN BANKREVISEUREN IN BELGIË}

Sedert geruimen tijd lag het in mijn voornemen op mijn artikelen, opgenomen in het M.A.B., jaargang 1935 No. 8 en jaargang 1936, No's 2 en 3 onder denzelfden titel, terug te komen, teneinde het resultaat van de wet op de Banken en de contrōle door beëedigde reviseuren, nadat deze enkele jaren gewerkt had (deze wet is thans vier jaren van kracht) te kunnen beoordeelen. Tot mijn leedwezen kon ik door de mobilisatie echter niet eerder aan mijn plan uitvoering geven, aangezien mijn tijd ook thans nog beperkt is, zal ik dit artikel bekorten tot een beschouwing van de werking van bedoelde wet in verband met:

1e. Het beroep van den bankreviseur(accountant);

2e. De opleiding van den bankreviseus (accountant);

3e. De werkzaamheden van den bankreviseur (accountant); en de resultaten van deze wet;

4e. De meening in bankkringen over deze wet;

5e. De resultaten van de contrôle door de bankreviseuren.

Ad 1e. Het beroep van den bankreviseur (accountant).

In de bovenaangehaalde artikelenreeks wees ik er op pag. 115 van No. 8, jaargang 1935 van het M.A.B. op, dat over het algemeen een Belgische boekhouddeskundige (ExpertComptable) zoo om ende nabij te vergelijken was met iemand in het bezit van een volwaardig praktijk diploma. In bevoegde kringen verwachtte men, mogelijk was hier het woord ",hoopte" beter op zijn plaats geweest, dat het beroep zich snel in gunstigen zin ontwikkelen zou.

Van eenigen maatregel daartoe was echter geen sprake. Het zij nogmaals gezegd, officiëel werd in de Memorie van toelichting op deze wet, en bij gesprekken, welke wij met bevoegde instanties hadden, herhaaldelijk verkondigd, dat, nu men tot officiëele erkenning en dito benoeming van bankreviseuren overging, en hen speciale bij deze wet voorziene werkzaamheden opdroeg, waardoor behoorlijke inkomsten genoten werden, kon verwachten, dat er zich geleidelijk een stand van op hoog peil staande bankreviseuren zou ontwikkelen.

Het heeft niet zoo mogen zijn. Ten opzichte van het accountantsberoep in België in het algemeen heeft deze wet zelfs een averechtsche werking gehad. Want wat gebeurde er nu? De boekhouddeskundigen, die een academische studie ${ }^{1}$ ) hadden, kwamen alle in aanmerking voor bankreviseurs, zoomede de beste praktische boekhouddeskundigen en $z \mathrm{ij}$, die een groot aantal jaren vooraanstaande functies in bankbedrijven hadden bekleed. Als overige boekhouddeskundigen bleef derhalve het overschot, en doordat de beste groep een nieuw

1) Hierbij zij opgemerkt, dat deze academische studie vrijwel een handels- en geen of niet voldoende bedrijfs-economische- en rekening-wetenschappelijke opleiding betrof. werkterrein kreeg, werd de overblijvende groep nog aangevuld met een groot aantal boekhouddeskundigen (Experts-Comptable), die voordien geen kans zagen als zoodanig werk te vinden.

Het spreekt vanzelf, dat deze gang van zaken niet bevorderlijk was voor een behoorlijke honoreering van de accountantswerkzaamheden. Deze honoreering was voordien in een land met een lagen levensstandaard als België toch al miniem; voordien werd een declaratie van $f 5 .-$ tot $f 6$. - per dag vaak uitermate hoog genoemd.

Door bovengenoemde omstandigheden wordt deze belooning buiten de bankkringen en de grote ondernemingen thans, ning buiten de bankkringen en de groote ondernemingen thans, niettegenstaande de gestegen index-cijfers, als buitensporig hoog beschouwd. Een verdere beschouwing van het accountantsberoep in België lijkt mij, van het standpunt van den $\mathrm{Ne}$ derlandschen accountant, na deze uiteenzetting overbodig.

\section{Ad 2e. De opleiding van den bankreviseur (accountant).}

. En bestond er in België, voor het in werking treden van de Bankwet, geen accountants opleiding, ook nadien is hierin niet veel verbetering gekomen, en zal ook niet komen, zoolang men het beroep niet op een hooger niveau weet of met alle ten dienste staande middelen tracht te brengen. Ongeveer ten tijde van het in werking treden van de Bankwet werden te Antwerpen door het V.A.V., een accountantsopleiding en examens ingesteld. Deze examens bestaan derhalve nog te korten tijd om reeds belangrijke resultaten opgeleverd te kunnen hebben. De opleiding van de bankreviseuren geschiedt voor het grootste gedeelte nog aan de school voor Hooger Handelsonderwijs te Brussel. Zooals reeds kort in een noot vermeld (zie pag. 38 jaargang 1936 M.A.B.) leidt deze school in het algemeen voor den handel op, en wordt er bijvoorbeeld aan warenkennis meer aandacht besteed, dan aan bedrijfseconomie en zeker aan de rekenings-wetenschap of contrôleleer en cijfer-beoordeeling. Het doel dezer onderwijsinrichtingen is trouwens commerciëele krachten op te leiden.

Ook komen voor benoeming tot bankreviseur in aanmerking, zij, die een aantal jaren een vooraanstaande functie in de bankwereld bekleed hebben. Ik wil niet betwijfelen, dat deze menschen geschikt zijn voor de uitoefening van de functie van bankreviseur, de accountantsopleiding in het algemeen is er echter niet mee gebaat. Tenslotte is ook de mogelijkheid voorzien door opleiding via de vereeniging van bankreviseuren. Tot mijn spijt moet ik bekennen, dat van de resultaten hiervan mij niets ter oore gekomen is, zoodat ik grond heb aan te nemen, dat de behaalde successen niet al te groot zullen zijn.

De tweetaligheid is in België ook een belemmering voor de opleiding, aangezien men op elk gebied, zoo ook op dat van het accountantswezen, in principe al een tweetal vereenigin gen, opleidingen en examens heeft, namelijk een Fransche en een Vlaamsche. Dat deze splitsing het beroep niet ten goede komt, behoef ik hier niet nader aan te duiden. (Zie ook pag. 82 , jaargang 1936 van het M.A.B., waarin zulks ook van Belgische zijde toegegeven wordt).

De levensstandaard speelt bovendien ook nog een belangrijke rol in deze materie. Elke opleiding moet bekostigd worden. waar en tengevolge van den lagen levensstandaard en tengevolge van de mindere waardeering van de kantoorwerkzaamheden, de salarissen van jonger kantoorpersoneel in België zer laag zijn, is het voor deze categorie vrijwel uitgesloten, dat zij zich de weelde van het bekostigen van een opleiding kunnen getroosten.
Ad 3e. De werkzaamheden van den bankreviseur (accoun. tant).

Bij onze gesprekken, die wij hierover met buitenstaanders 